\title{
Forensic Research in Sri Lanka: Is the Magistrate's Authority Essential to Use Medico-Legal Records Retrospectively?
}

\author{
Kodikara $\mathrm{S}^{*}$ \\ Department of Forensic Medicine, Faculty of Medicine, University of Peradeniya, Sri Lanka
}

Received: 01 June 2021, Revised version accepted: 24 June 2021, Published: 30 June 2021. *Corresponding author: Kodikara S*, $\triangle$ email: skodikara@pdn.ac.lk (D) ORCID: https://orcid.org/0000-0002-3790-0489

Cite this article as: Kodikara S. Forensic Research in Sri Lanka: Is the Magistrate's Authority Essential to Use Medico-Legal Records Retrospectively? Medico-Legal Journal of Sri Lanka. 2021;9(1):50. DOI: http://doi.org/10.4038/mljsl.v9i1.7441

Copyright: @ 2019 with the Medico-legal Journal of Sri Lanka.

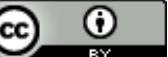

This is an open-access article distributed under the terms of the Creative Commons Attribution 4.0 International License, which permits unrestricted use, distribution, and reproduction in any medium provided the original author and source are credited.

Forensic research has widely and drastically increased in the recent past and is now in the civilized pathway adhering to ethical principles. Some retrospective forensic research are based upon information given by patients who were solely referred for medico-legal examination either by courts or Officer-in-Charge (OIC) of a police station. According to the sub-section 122 (1) of the Criminal Procedure Code of Sri Lanka,[1] the sole objective of such referral is to obtain medico-legal information in order to weigh the evidence, to explore the possibility of further prosecution and to assists the courts for a fair administration of justice. Through the person referred by police/courts, the forensic physician requests consent for medico-legal examination. This is to fulfill ethical and legal requirements. This consent is very specific. Before requesting consent, the examinee is informed that the information is taken and examination is done solely for medico-legal purposes and the findings will be submitted to the relevant OIC of the police station and thereafter to courts. The only purpose of this procedure is fair administration of justice. Upon agreeing to this, the examinee would give consent for what he/she has been requested.

This routine consent does not include consensus to perform research using the said data unless it is specifically requested. Therefore, using such retrospective data for research fundamentally violates the ethical principle of autonomy and is also against the specific legal objectives stipulated by sub-section 122 (1) of the Criminal Procedure Code of Sri Lanka.
When retrospective data is taken from clinical records of a patient who came to a health institution for treatment purposes, it is mandatory to obtain the permission of the head of the relevant institution in order to use such data for research and is strictly inquired before ethical clearance is given. In such perspectives, it is justifiable to consider that the guardian of the said data is the head of the said institution.

In a similar manner, the guardian of the data set of the patients referred under the Criminal Procedure Code is the magistrate of the respective jurisdiction. Therefore, the author suggests that a written authority should be taken from the relevant magistrate in order to use such data for research. This will preserve the basic ethical rights of such victims such as autonomy, beneficence, non-maleficence, justice and confidentiality.

\section{References}

1. Code of Criminal Procedure Act (No 15 of 1979), Sri Lanka. 